\title{
“They never listen": Towards a grounded theory of the role played by trusted adults in the spiritual lives of children
}

\author{
May L. Karlsen ${ }^{\mathrm{a}}$, Adrian Coyle ${ }^{\mathrm{b}}$, and Emma Williams ${ }^{\mathrm{c}}$
}

\author{
${ }^{\mathrm{a}}$ West London Action for Children, 15 Gertrude Street, London, SW10 0JN, United \\ Kingdom \\ Tel: +44 (0)207352 1155
}

Email: may@wlac.org.uk

bshool of Psychology, University of Surrey, Guildford, Surrey, GU2 7XH, United Kingdom.

Tel: +44 (0)1483 686896

Email: $\underline{\text { A.Coyle@surrey.ac.uk }}$

${ }^{\mathrm{c}}$ School of Psychology, University of Surrey, Guildford, Surrey, GU2 7XH, United Kingdom.

Tel: +44 (0)1483 686909

Email: e.i.williams@surrey.ac.uk

The full reference for the published version of this article is:

Karlsen, M. L., Coyle, A., \& Williams, E. (2014). 'They never listen’: Towards a grounded theory of the role played by trusted adults in the spiritual lives of children. Mental Health, Religion \& Culture, 17(3), 297-312. DOI

10.1080/13674676.2013.798781

\footnotetext{
*Corresponding author. Email: may@wlac.org.uk
} 


\title{
“They never listen": Towards a grounded theory of the role played by trusted adults in the spiritual lives of children
}

\begin{abstract}
This qualitative study addresses the lack of research into the role of trusted adults in the spiritual lives of children. Semi-structured interviews were conducted with nine children from a British primary school and the data analysed using a grounded theory approach. Six categories were identified outlining the reciprocal relationship of unavailability and withholding between children and their trusted adults and how children made sense of spirituality in the absence of explicit guidance. It was found that the children had little opportunity for negotiating a shared understanding or experience of spirituality with adults and, as a result, either preserved an isolated and secret sense of spirituality or accepted what they observed to be their trusted adults' stance. The practical and theoretical implications of the children's responses in the absence of trusted adults are discussed and recommendations are made for practice and future research.
\end{abstract}

Key Words: children’s spirituality; religious beliefs; spiritual development; spiritual guidance. 


\section{“They never listen”: Towards a grounded theory of the role played by trusted adults in the spiritual lives of children}

\section{Introduction}

Spirituality has been recognised as important to children's healthy development by all major childcare institutions (Scott, 2003). In the United Nations Convention on the Rights of the Child (1991), the child's spiritual development is recognised alongside moral, mental and social development as an aspect of children's lives that is worthy of protection and nurturing. The increasing interest in the spiritual capacities of children is also evident in literature and research describing their rich and complex spiritual lives (e.g. Coles, 1990; Hart, 2004; Robinson, 1983). In a study by Hay and Nye (1998), for example, from the age of six years children were found to grapple with 'big questions' to do with the nature of God and meaning of life, recount sudden experiences of profound compassion, insight or connection, and describe feeling comfort as well as distress associated with their spiritual beliefs and experiences. Despite this recent surge of interest and child-focused professionals' advocacy of attending to the 'spiritual needs' of children as distinct from religious education or development (e.g. Hufton, 2006; McSherry \& Smith, 2007), little is known about how such considerations might be achieved in practical terms. This article approaches the topic from a psychotherapeutic perspective with emphasis on how psychologists, therapists and counsellors working with children can meet their 'spiritual needs' but with the hope that the findings can be of relevance to practitioners working with children in diverse contexts.

From a developmental perspective, four main approaches to childhood spirituality can be discerned, based on different epistemological underpinnings: 
Fowler's (1981) faith development theory, the socio-biological approach (Hardy, 1979), attachment theory as applied to spiritual development (Rizzuto, 1979), and cognitive-cultural theories (Boyatzis, 2005). Although these approaches have the potential to inform therapeutic practice with children and the promotion of children's spiritual development, few explicit references have been made to their practical implications. Moreover, compared to the rigorous commitment to the study of children's cognitive and emotional development, spirituality remains a relatively marginal and overlooked topic within these domains (Oser et al., 2006; Roehlkepartain et al., 2006).

Greater insight into ‘children's spiritual needs' and the roles adults play in meeting those needs can be found within the psychology of spirituality and religion. In Cole’s (1990) extensive research into children's spirituality, parents, aunts, uncles, ministers and religious teachers were all referred to in children's accounts, mainly as a source of information that was drawn upon to make sense of spirituality. This could indicate that adults acted as teachers, mentors or guides for the children, although the study did not explore the nature or dynamics of these relationships in detail. Other research into the process of religious socialization suggest that mothers tends to play a more central role than fathers (Boyatzis \& Janicki, 2003; Myers, 1996) and that children are active agents in engaging with the topic and developing an individual stance (Boyatzis \& Janicki, 2003; Prentice \& Gordin, 1986). In their study on religious communication between parents and children, Boyatzis and Janicki (2003) found the relationship between parents and children to be characterized by reciprocity and mutual interest as children initiated conversations more often than adults.

Most of the literature on this topic, however, seems to focus on the ways in which adults can encourage spiritual development in children through education, 
recommended activities and discussions (e.g. Hay \& Nye, 2006) and little is understood about the actual processes that take place between children and adults. This is in stark contrast to other developmental domains, such as emotional development where rich and diverse theoretical models have been developed to guide therapeutic work with children. If child therapists and other practitioners working with children are to take the recommendations made by child care agencies seriously, more research and theory are required on the spiritual needs of children and how spiritual development may be nurtured by trusted adults in their lives. The present study aims to address this lack of theory and research.

In addition, there is a failure to take into account children's perspectives when attempting to understand their experiences, a tendency that appears endemic to the entire field of developmental psychology (Fiese \& Bickham, 1998). The present interview-based qualitative study responds to the plea made by Grover (2004) to “regard children as experts on their own subjective experience” (p.91). In a similar vein, the terms 'spirituality' and 'religion' remained open to the children's understanding and perspectives in this study rather than adhering to any particular definition or theoretical orientation. It is, however, unavoidable that certain assumptions about the topic under investigation shape the initial focus of the research. As the study is largely informed by previous research on the topic carried out by Hay and Nye (1998) which favoured a socio-biological approach, the initial research question was formed with this approach in mind. Here spirituality is understood as an innate, naturally-evolved capacity which can nevertheless be suppressed and denied expression by cultural trends and processes (Hay, 2006).

The present study primarily aimed to contribute to the process of developing a theory about the potential role 'trusted adults' play in the spiritual lives of children in 
an attempt to gain a child's perspective on how adults may support (or otherwise) their spiritual development. The term 'trusted adult' was used generically to describe any adults who emerged during the interviews as playing a significant role in the participants' lives overall. The study sought to go beyond descriptive accounts of influence and move towards an explanatory understanding of the underlying processes. It was hoped that gaining such insights would provide child care practitioners with greater understanding of the processes underlying a child's spiritual development. More specifically it was hoped that these insights might inform child therapists on how to adopt an encouraging and nurturing role during therapy. The research question that formed the focus of the present study is 'What role, if any, are trusted adults said to play in the spiritual lives of children recruited from a British primary school?’

\section{Method}

\section{Participants}

Nine children took part in the study, four of whom were male and five female. They were all aged between six and seven years and recruited from the same class in a primary school in south east England. The school was a non-religious school with a much higher than average percentage of children entitled to free school meals (23\%). Although the school was located in a culturally and socio-economically diverse area, seven out of the nine participants were of White-British background whilst the remaining two participants were of British-Chinese and British-Turkish backgrounds. The religious affiliations of the participants' families are outlined in Table 1.

[Table 1 about here] 
As part of the participant exclusion criteria, children with moderate to severe learning difficulties were not invited to take part in the study. Neither were children who were going through a particularly difficult time due to trauma, bereavement or stressful circumstances in the family. The latter exclusion criterion was adopted to safeguard children from emotional distress during the interviews and was applied through consultations with teachers as well as specified in the recruitment letter sent to parents.

The participating children differed widely in their understandings and expressions of spirituality, and several different 'types' of spiritual expressions were discerned in the participants' accounts. Table 2, in which individual children are identified by pseudonyms, has been presented in order to provide some context for the quotations presented in the results section. This is not to suggest that there are categorical distinctions between different spiritual expressions: rather than seeing them as such, it would be more useful to think of them as points on a continuum in much the same way as Hay and Nye (1998) suggested in their study.

[Table 2 about here]

\section{Data generation}

When a favourable ethical opinion for the study was obtained, two pilot studies were conducted to prepare the interview schedule and test the materials. These interviews were not included in the analysis. The parents of eligible children were contacted by post. The recruitment package comprised an introductory letter, an information sheet and a consent form. 
Once consent had been obtained from parents and children, the children were invited to join the interviewer (MLK) for a one-to-one conversation. The interviews were digitally recorded and lasted on average 30 minutes but varied from 10 to 60 minutes depending on how long the child was able or willing to engage. Individual children were interviewed up to four times, depending on the time, availability and interest of the child.

The semi-structured interview schedule featured open-ended questions organised around a series of 33 pictures. These pictures had been chosen for their potential to elicit associations relevant to spirituality in a general sense, such as the images of a child holding a butterfly, a dark sky lit by the northern lights, and a girl looking thoughtfully at her own reflection in a window. In addition to visual images, both the child and the interviewer were free to use drawings to complement their verbal expression. The interview schedule was divided into three parts. The first part was designed to build trust by asking general questions about the child's life. In the second part, the topic of spirituality was introduced and the child's personal stance and experiences explored. The third part focused on the particular roles played by trusted adults in the participants' spiritual lives. The interview schedule was applied flexibly and the conversations were mainly child-led.

\section{Analytic procedure}

The analysis was conducted by a team of three researchers who each brought a particular expertise relevant to the research topic. One researcher brought a developmental perspective (EW), another contributed from the perspective of the (social) psychology of religion (AC), and a third contributed from the perspective of counselling psychology with particular experience of working with children (MLK). 
MLK acted as the principal researcher, undertook data generation and led the analysis in collaboration with the other team members to maximise its coherence, persuasiveness and credibility. The analysis aimed to achieve a credible reading of the data through a negotiation of the 'best fit' between possible interpretations and the data.

The interviews were transcribed and analysed using the constructivist version of the grounded theory approach formulated by Charmaz (2006). Based on the classic version of grounded theory by Glaser and Strauss (1967; Glaser, 1978) this approach assumes a relativist position, acknowledging the constructed nature of human experience and the multiplicity of possible standpoints of both participants and researchers. As such it sees the participants' accounts as a joint construction rather than a reflection of an objective reality. It takes a reflexive stance towards the interrelational processes taking place in the field and subsequent analytic engagement and theory development. In accordance with the grounded theory approach, the analytic procedure followed a continuous recursive movement between data collection, analysis, reflections and theory development (Payne, 2007).

After several readings, the first few transcripts were coded in their entirety using the 'constant comparative method' (Glaser \& Strauss, 1967) while sticking closely to the data and language used by the children. These codes were grouped into larger categories which served to inform subsequent interviews. As the data were so diverse, the entire data set was subjected to open coding followed by a process of grouping these codes and re-working them through axial coding (Strauss \& Corbin, 1990; Charmaz, 2006). Finally, data were analysed using theoretical coding (Glaser, 1978; Charmaz, 2006), conceptualizing "how the substantive codes may relate to each other as hypotheses to be integrated into a theory” (Glaser, 1978, p.72). 
Due to limited time and access, it was not possible to use 'theoretical sampling' in the reciprocal processes between collecting and analysing data and, as such, the study does not claim to have reached 'saturation', as indicated in title of this article 'towards a grounded theory'. Instead this research is intended as an initial insight into some of the meaning-making strategies and capacities among children in relation to the research topic and as a contribution towards the development of a more elaborate picture by subsequent researchers.

\section{Criteria for evaluation}

This study may be evaluated according to the guidelines for qualitative research identified by Yardley (2000). Thus the study aimed at being sensitive to context, 'committed and rigorous' in engaging with the research topic and data, being 'transparent and coherent' in the research process and taking into account the 'impact and importance' of the research findings. Additionally, the research may be evaluated according to criteria more specific to a grounded theory study, i.e. that the theory has credibility, originality, resonance and usefulness and that it is consistently and convincingly grounded in the data (Charmaz, 2006).

\section{Results $^{1}$}

The analysis produced six categories relevant to the research question as illustrated in Figure 1. At the core of the research findings lies the reciprocal relationship of unavailability and withholding between trusted adults and children ('Trusted adults

\footnotetext{
${ }^{1}$ In the quotations presented throughout this section, underlining has been used to indicate words that were vocally emphasized by the participants; empty square brackets [ ] indicate where material has been omitted for editing purposes; material within square brackets is usually clarificatory but sometimes indicates short interjections from one speaker during another speaker's turn; and three dots indicate short pauses in speech. Care has been taken not to change the meaning of the participants' accounts.
} 
unavailable for child' and 'Child withholding from trusted adults'). These two categories represent the face-to-face, dyadic relationship between adult and child and what unexpectedly transpired to be the lack of communication between them when it came to spiritual matters. It was this overwhelming absence of trusted adults in the children's accounts that focused this analysis on the implicit messages passed on and accepted by the child and the ways in which they reportedly experienced and made sense of spiritual matters in isolation.

[Figure 1 about here]

Due to space constraints, only two whole categories and parts of a further two categories will be presented in detail, namely ' Trusted adult unavailable for child', 'Child withholding from trusted adult', 'Child accepting trusted adult's implicit guidance' and 'Child isolating themselves and making sense of spirituality alone' respectively.

[Table 3 about here]

\section{Trusted adult unavailable for child}

None of the participating children reported speaking openly with adults about their spirituality, be it the philosophical questions pondered by children in the third type in Table 2 or the intense experiences and insights reported by children in the first. When asked why this was, the participants invariably responded that their trusted adults were not available when it came to spiritual matters. According to the children, the most common underlying reason for the adults' unavailability was that they were too 
busy. Therese, for example, explained that she could not share her questions about God with her mother because “My mum doesn’t get time because she really, all she does is just lie down on the sofa and says 'Tomorrow'”. She went on to explain that she could not approach her father either about her questions because "Dad is always at work, he always cooks dinner and he always shouts at me.” It seemed as though Therese's parents were experienced as too busy with everyday routines and lacking the emotional availability that Therese needed to open up about her spirituality. Even her grandmother was reportedly unavailable as there were always other children around, allowing no space for Therese to air her intimate thoughts in private. Similarly, Ben contended that his Sunday school teachers were too busy instructing him what to do to listen to him:

Because they just tell you what to do. "Do this, do that.” [ ] And they don’t listen. [ ] They never listen.

Ironically, although Ben reportedly enjoyed every other aspect of church life, it was the service specifically aimed at children that he least approved of and seemed to find the least rewarding. He seemed to dislike the didactic approach adopted by the Sunday school teachers which allowed little input or active participation from him and he later asserted that Sunday school would be better if the adults there listened more and talked less.

Annie also expressed a liking for church life and, despite coming from a family that was not religious and never attended religious services, she expressed a longing to spend time in a church. During this part of the interview she had been 
considering a picture of a girl lighting a candle and concluded that this was done in a church to 'receive the good' from God.

Interviewer: Do you ever go to church and light candle lights for God?

Annie: $\quad$ No. No, because my mummy and daddy won't let me.

Interviewer: What do you mean?

Annie: $\quad$ They, they, they...they go and watch TV and there's no place to do it. [ ]

Interviewer: Do you ever go to church?

Annie: $\quad$ No. I only walk up the Eiffel Tower with my mummy and daddy.

From Annie’s comment, the parents' unavailability did not simply come down to lack of time but also lack of priority and interest. It is interesting that whilst Annie's parents were not religious, Annie herself expressed a strong religious affiliation and appeared to have a religious identity independent of her parents and seemingly of any other trusted adults. Whilst there are theories that understand spiritual and religious beliefs in terms of cultural traditions passed from one generation to the next (e.g. Boyatzis, 2005), there are also studies that have found children to be capable of acquiring beliefs that do not correspond to their parents’ (Prentice \& Gordin, 1986) and Annie's account seems to exemplify this. Thus the children in this study were not necessarily passive recipients of adults' guidance but, on the contrary, seemed capable of taking an active and personal stance towards spirituality. This was also evident in 
the way nearly all of the participating children seemed to actively reciprocate their trusted adults’ unavailability by withdrawing and holding back.

\section{Child withholding from trusted adult}

It is, of course, possible that the children withheld from their trusted adults out of a personal preference rather than as a counter-reaction to their parents' unavailability. Simon, for example, seemed more interested in sharing his 'spirituality' with his friends than his parents. The reasons for this were not clear from his account. However, it is well known that friends become an increasingly important point of reference for children of Simon's age whilst parents' role tends to decrease in significance (Altman et al., 2002). As such it is possible that withholding from his parents was a natural step towards breaking away from them and 'growing up'. Interestingly, this did not feature strongly in the participants' accounts and Simon seemed to be the only one who shared his 'spirituality' with his friends. For the rest of the participants, their withholding seemed closely linked with the perceived unavailability of their trusted adults. Sandra, for example, withheld her experiences and thoughts out of a concern that it would make her parents sad. Here she had just recounted that she sometimes hears the voices of people who have passed away, especially her maternal grandmother's 'kind voice', which occasionally 'comes into her brain'.

Interviewer: And did you ever talk to your mum about your thoughts about death and about people...

Sandra: $\quad$ No, cause if I say that she'll be sad. That's why.

Interviewer: Mm. So you don’t want to talk to her about 
that. How about your dad? Do you talk to your dad about it? [ ]

Sandra: $\quad$ No, cause might people get sad.

From her account, Sandra seems to have learnt that talking about death has negative consequences and is therefore a topic best avoided. She was not alone in this respect: several participants expressed a lack of opportunities to talk about death and the deceased. Tina, for example, reported never having seen the grave of her deceased friend and emphasized several times during her interviews a wish to commemorate the dead and mark their departure. From their accounts, the topic of 'death' seemed to be taboo and something to be particularly cautious about during conversations. As 'spirituality' was described by most participants as closely linked with their beliefs and experiences related to afterlife and the deceased, it follows that a significant part of their spiritual lives was 'banned' from open conversations. Indeed, Hay and Nye (1998) suggested in their study that spirituality itself has become a 'taboo' from which society at large tends to shy away. This seems congruent with the complete lack of communication regarding spirituality reported in the present study. Thus adults' unavailability could be symptomatic of a cultural avoidance of things spiritual and the children's withdrawal a response to this.

The principle of reciprocity seemed to apply also within the relationship between interviewer and participant. Thus whilst some participants decided to open up after a period of getting to know the interviewer, others were much more cautious and for them it seemed the interviewer never earned enough trust to be allowed into their private space. Here towards the end of his last interview Ben had just disclosed that he did not like Sunday school as the teachers there 'never listen': 
Interviewer: They never listen... What would you want to say to them?

Ben: $\quad$ Other things you wouldn’t want to know about.

Interviewer: What kind of things?

Ben: $\quad$ Other things you wouldn't want to know about.

Interviewer: Mm... Why do you think I wouldn't want to know?

Ben: $\quad$ Because you wouldn’t.

Whilst Ben undoubtedly knew that the interviewer was very interested in listening to him and that this was, in fact, the purpose of the interview, he remained unconvinced and continued to withhold the more personal nature of his spirituality. This tendency to withhold was evident with other participants who started the interviews with apprehension, uncertainty and denial but later went on to give vivid accounts of their spiritual experiences. Sandra, for example, answered at the beginning of her interview that she never 'wishes' to God (her terminology for praying), only to reveal a little later that she frequently talks to God. Similarly, Annie was reluctant at first to admit that she prays to God. In this quotation she explicitly states that her initial withholding is not specific to the interview context but that she, in fact, has never before spoken about her spirituality:

Interviewer: So do you ever pray?

Annie: [In a slower, lower voice] I never pray.

Interviewer: What kind of things do you think... 
Annie: [ [Interrupts] I've never, I’ve never told

anyone I pray.

As a result of this reciprocal relationship of unavailability between children and adults in the sample, the participants seemed to respond in two main ways as can be seen from Figure 1, namely 'Accepting trusted adults' implicit guidance' and 'Isolating themselves and making sense of spirituality alone'. Whilst both responses could be found in any one interview and as such were not mutually exclusive, the participants' accounts seemed to be dominated by one over the other. Thus children who accepted trusted adults’ implicit guidance described being spiritually isolated to a much lesser extent and vice versa. The following section will look at these two responses in turn.

\section{Child accepting trusted adult's implicit guidance}

Even though trusted adults did not appear to offer direct guidance or support to the participating children, they still featured in the children's accounts albeit in more implicit and indirect ways. This 'guidance' appeared to take the form of information and messages from the adults that were picked up and integrated by the children. These messages were not necessarily intentional on the adults' part and certainly not mutually defined but nevertheless continued to exert a powerful influence on the child's spirituality. Of course, there are innumerable ways in which trusted adults influence a child's overall development and spirituality cannot be seen as separate from this context. Indeed, Fowler (1981) saw the first stage of faith development as characterized by the infant learning to either trust or mistrust their environment depending largely on the quality of care they receive. This study, however, does not attempt to give an exhaustive account of all the implicit processes taking place 
between adults and children pertaining to spirituality but rather it introduces some of the ways in which the children seemed to draw on their trusted adults' implicit messages in their own accounts of spirituality.

\section{Identifying with trusted adult}

In response to the implicit guidance of trusted adults, the children would employ different meaning-making strategies in their attempt at making sense of spirituality in relation to their own sense of self. Tom, for example, gave a compelling account of how he identified with the spiritual stance adopted by one particular trusted adult he greatly admired, namely his father. Thus, rather than expressing a personal stance towards spirituality and religion, it seemed as though Tom used religion to assert a particular 'male identity' that was similar to his father's. At one point he exclaimed, "If God was here right now, I'd kill him”, and when asked why, he explained "Because earth is no fun”. Tom later explained that his mother believed in God but his father did not and he explicitly said that he wanted to be 'bad like his dad'. It was clearly important to him to be associated with his father and it seemed just as important not to be associated with his mother. In one particularly striking comment, it is possible to discern his ultimate disassociation from his mother and identification with being 'bad':

I don’t think I was really born, I think I just fell from hell.

Tom repeatedly ridiculed religious people and in this way simultaneously reaffirmed his own sense of identity. According to Tom, he had never actually spoken to either his father or mother about religion but instead appeared to observe their attitudes 
towards spirituality and used it as an important resource towards constructing a particular identity.

Adopting the spiritual stance of trusted adult

Despite reportedly never talking openly to adults about his spirituality, Ben's accounts were also dominated by the guidance of his trusted adults, albeit in a slightly different way than in Tom's case. Whilst there were many similarities in their accounts, Ben appeared to dispassionately adopt the spiritual stance of trusted adults in a manner more associated with compliance and conformity than with an active process of identification. Just before the excerpt below, Ben had explained that God created all the stars so that humans could enjoy them, when he suddenly interjected:

Ben: $\quad$ God is not only in one place, he’s everywhere.

Interviewer: Is he everywhere at the same time?

Ben: $\quad$ Yeah.

Interviewer: How do you know that?

Ben: $\quad$ Cause I go to Sunday school.

Ben was highly knowledgeable when it came to Christian teachings and, whilst his comments were theologically correct and at times surprisingly sophisticated, they seemed to lack the sense of personal conviction and spontaneity which characterized the accounts of some other participants. In their research, Hay and Nye (1998) made a similar observation about some participants who came from religious families and appeared highly knowledgeable but at the expense of a personal connection with the material they were recounting. Ben's account seems to be consistent with cognitive- 
cultural theories of spiritual development (Oser et al., 2006) suggesting that the reason why children develop spiritual beliefs is because they are introduced to them by trusted adults. It seemed as though he was recounting what he had been taught rather than sharing his own view which could explain why he seemed much less comfortable when asked about the more personal nature of his spiritual life.

Interviewer: Oh, you know many things about God and Jesus.

Ben: $\quad$ Yeah.

Interviewer: Have you met him? [ ]

Ben: $\quad$ Well, I don’t...has he told other people to do it?

Interviewer: Like whom?

Ben: $\quad$ Mum, dad, [indecipherable]. Perhaps

babysitters know.

From this and later comments, it seems as though Ben saw adults as spiritually superior and their knowledge as more trustworthy than his own, which indeed would be the case if his understanding relied solely on the knowledge of adults rather than personal experience or inference.

Although Ben’s Sunday school teachers had an explicit role as spiritual guides or teachers, he still perceived them as unavailable to hear him, as illustrated in his previously quoted comment: “They never listen”. Rather they appeared as adults who passed on knowledge about spirituality, leaving limited room for Ben to negotiate or contribute. This reported attitude resonates with many theories of spiritual 
development, which see children as spiritually immature and in need of instruction or guidance from adults (e.g. Helminiak, 1987; Kwilecki, 1999). Indeed, Ben’s account seems to reflect the widespread notion within Judaeo-Christian theories that spiritual development really only starts in earnest in adolescence and that children's spirituality remains relatively dormant until they reach a psychologically more mature age. For both Tom and Ben, whose accounts appeared to lack a personal conviction, it seems possible that a more integrated and personal stance towards spirituality could be negotiated at a later stage of development. On the other hand one may wonder whether, given the opportunity, they might currently have engaged with the material at a more personal level.

\section{Projecting trusted adult onto the spiritual world}

The participants' accounts indicated that although adults reportedly did not make much of an effort to provide spiritual guidance, they still remained hugely influential in the children's understanding of God and the spiritual world at large. Several of the children described God as a father figure with features that seemed to represent a typical authority or 'trusted adult' in their lives. Indeed, some children used the same words when describing God as they had used to describe their parents. For Ben and Annie, this meant that God was represented as 'too busy' to play with or listen to them, much like how they perceived their parents.

Seeing God as a father figure has been a recurring theme within the literature on children's spiritual beliefs (e.g. Coles, 1990; Goldman, 1965). One theoretical account of this theme is given by Rizzuto (1979) in her work on attachment theory as applied to representations of God, which implies that primal attachment figures tend to be reflected in or projected onto the relationship to God (see Kirkpatrick's related 
work with adults: for example, Kirkpatrick, 1995). This certainly seemed to resonate with the participants’ accounts, although the projections did not appear to be limited to representations of God. Instead they tended to include images of afterlife and the spiritual world at large. Sandra, along with Therese and other children, described heaven as a 'homely' place with the inventories and daily routines one would expect to find in their own homes.

....and if they [people in heaven] had a room to sleep God would like make food. The person would eat it and the picture of the family they could put it somewhere.

Conversely, hell was described as a place of punishment in terms of the disciplinary measures traditionally used by parents, teachers and society at large:

Annie: $\quad$ But in hell you, they get beaten by people. Like people, people who went to jail, people who only get three chances left.

Interviewer: They get three chances?

Annie: $\quad$ If they break one, they only get two left.

Interviewer: Who...what do they break?

Annie: $\quad$ The rules.

It seems the children's projections of trusted adults and their immediate social environment played an important role in the way in which they represented God and the spiritual world at large. This seems to suggest a strong 'psychological' element to 
the participating children's spirituality and a tendency to make literal interpretations of what in religious terms is a symbolic representation of God as father. It was this apparent literal interpretation of religious accounts which led Goldman (1965) to suggest that children were not psychologically ready for religion. However, although there seemed to be a clear projective element in many of the participants' descriptions of God and the spiritual realm, this did not seem to exclude a personally and spiritually rewarding relationship with God as suggested by Annie in the excerpt below. (When Annie refers to 'Amira', she is talking about a nanny who died a few years previously and who reportedly visits Annie at night in the form of a 'spiritual guide'.)

Annie: $\quad$ God said that I could be the new ruler [in heaven].

Interviewer: Really?

Annie: $\quad$ Yeah, I am his daughter.

Interviewer: You're God's daughter?

Annie: $\quad$ Yes, because my, well, Amira said that I could be one of a kind when I grow up.

\section{Child isolating themselves and making sense of spirituality alone}

For some of the children, accepting adults' implicit guidance seemed to dominate their accounts through the various strategies described above. For others, however, the unavailability of adults seemed to lead them to isolate themselves spiritually, not just from trusted adults but also classmates, siblings and people more generally. Annie, for instance, according to her comment below, feared that she would be met 
with suspicion and disbelief if she were to share her spiritual experiences and was therefore very careful not to speak about them to anybody:

Interviewer: You don’t want to tell anyone?

Annie: $\quad$ No.

Interviewer: You're telling me, though.

Annie: $\quad$ Cause I know that you won't tell anyone.

Interviewer: [ ] So if you had someone who said that they would never tell anybody, would you like to talk to them?

Annie: $\quad$ No.

Interviewer: No?

Annie: $\quad$ No, cause they'll just lie.

Interviewer: Oh, you can't trust them?

Annie: $\quad$ No, cause they are like...they don't believe in a girl who comes....who... who comes... cause they'll think I'm telling fibs.

Therese also seems to isolate herself spirituality but for slightly different reasons than Annie.

Interviewer: Do you think some people meet God?

Therese: No, because he is up in heaven and sometimes people lie because they think they've seen God but they don’t. They just smile or they think 
it's...they trick people and, and sometimes

people trick me that they've seen God and I

don't believe them.

From these accounts it seemed as though Annie was withholding her spirituality because she is worried about being accused of lying, whilst Therese withheld her spiritual concerns out of fear that she will be lied to. What both Annie and Therese appear to have in common is an insecurity and defensiveness about their experiences and an underlying suspicion and fear that people cannot be trusted with their particular expressions of spirituality. This emerged as a common feature in the participants' accounts and one may wonder whether the apparent lack of openness with trusted adults regarding spiritual matters serves to engender this general attitude of mistrust.

The reported effects of 'spiritual isolation' on the child seemed to vary within the sample but there appeared to be elements of both affirmative and more detrimental consequences. Thus whilst spiritual experiences seemed to bring great joy, for several of the children their spiritual isolation also seemed to be maintained by a feeling of fear, confusion and loneliness. According to Annie’s quotation below, for example, her spiritual experiences were intermingled with nightmares of evil plans and violent devils. When she was about to say something that was 'extra secret' during her interviews, she preferred to write it down on a white board and ask the interviewer to read it out aloud:

Interviewer: [Reads from the board] "Devils scare me in

$$
\text { my...dream” }
$$


Annie: $\quad$ Cause they make me have... when I have... what I don't like when they put in my head is dreams.

Interviewer: Do they?

Annie: $\quad$ Mmm

Interviewer: What kind of things do they put in your head?

Annie: $\quad$ They put...turn my whole family into spiders.

This spiritual isolation and lack of available forums for talking openly about spirituality led some children to find alternative outlets for their ideas. Therese, for example, explained that she used to confide in her guinea pig:

And it's really like my guinea pig doesn't know about these things but [ ] I still tell him about them. He just doesn’t understand talking.

Whilst Therese reportedly recognised that her guinea pig could not actually understand her, let alone provide her with any answers, it did seem to serve a purpose simply by allowing her the space to talk. After all, a guinea pig could not trick her with lies or false information like humans could and Therese seemed to consider this a safer space to air her concerns. Perhaps it also signifies the kind of space she would have appreciated with a trusted adult.

\section{A theory of reciprocal unavailability}

The provisional theory introduced in this article and illustrated in Figure 1 was developed based on the perceived unavailability of trusted adults with regard to spiritual matters as reported by the participating children. According to this theory, 
the children were left to make sense of their spirituality using the information and meaning-making strategies available to them without the explicit guidance of trusted adults. In this regard, the participants appeared to respond in two different ways. Some of the children responded mainly by accepting the implicit messages afforded by trusted adults, whilst others tended to hide their spiritual experiences and isolate themselves from others.

The first of these responses, 'Child accepting the implicit guidance of trusted adults', seems to encapsulate several different theories of spiritual development. For example, the process of adopting a particular spiritual stance introduced by a trusted adult could usefully be explained by a cognitive-cultural theory of spiritual development (Boyatzis, 2005; Oser et al., 2006), whilst attachment theory as applied to representations of God (Kirkpatrick, 1995; Rizzuto, 1979) could better account for the way trusted adults seemed to be projected into the child's spiritual world. These theories would explain spirituality and the role of trusted adults in very different terms and yet they seemed to apply to the participants' experience in a complementary way. Overall there was a sense that children who accepted the implicit guidance of trusted adults had available to them a shared and socially acceptable language of spirituality but seemingly at the expense of a more spontaneous and experiential spiritual expression.

The second response to the perceived unavailability of trusted adults, 'Child isolating themselves and making sense of spirituality alone', describes children whose accounts of spirituality were based more on personal encounters than preconceived knowledge. Thus their spirituality seemed more related to the profound religious experiences referred to by Hardy (1979) and Robinson (1983) rather than their religious beliefs. These accounts resonate with a socio-biological definition of 
spirituality (Hardy, 1979; Hay, 2006) seeing it as an innate capacity which does not necessarily require deliberate cultivation but which can nevertheless be stifled by destructive social processes. These children seemed to retain a spiritual freedom and spontaneity by isolating from others but also seemed to suffer from the lack of a socially acceptable way of expressing their concerns.

In simplistic terms, the theory suggests that the lack of open communication with adults forces children to either accept or reject their trusted adults' spiritual stance and language. This neglect and avoidance seems related to what Hay (1998) termed the 'social destruction of spirituality', which describes a process by which spirituality is culturally overlooked and gradually forgotten about. Without a forum in which children can express their experiences and concerns, it seems quite possible that their sense of spirituality will gradually wither or be habitually and enduringly ignored.

\section{Discussion}

A sample of nine participants is clearly not sufficient to reach a comprehensive understanding of the phenomena in question and as such it must be reiterated that the study aimed for an initial insight into the processes taking place in this neglected area of research. As 'theoretical sampling' was not an option due to practical constraints, none of the categories can be said to have reached 'saturation'. Furthermore, as the majority of the participants came from a White British background, their experiences of spirituality and relational dynamics with trusted adults are likely to represent a particular cultural perspective: children with different cultural backgrounds may have different experiences. As such, considerably more research is needed in this area before a comprehensive and widely applicable theory can be confidently advanced. 
Despite the lack of 'theoretical sampling' in the study, the participant sample was far from homogeneous but, on the contrary, was so diverse in their expressions of spirituality that it was at times difficult to find commonalities between them. As such, some of the categories had a weak evidence base in the sample as a whole and represented instead important features for some participants. Despite the diversity of the sample in terms of participants' spiritual expression and willingness to share, they all seemed to converge in one very important area, that is, none of them reported speaking openly to their trusted adults about spiritual matters.

The study highlights some general issues around children's spiritual development and the underlying relational dynamics that could develop between adults and children in this regard. It also highlights the potentially frightening and confusing effects of spirituality and the importance for children who struggle with this to have a 'safe space' where such experiences are openly talked about. By being mindful of the tendency for children to withdraw and of their sensitivity to the perceived availability of adults, psychologists and other therapeutic professionals should be able to enter into conversations with children in an open-minded and accepting manner. Thus rather than embodying the 'unavailable adult' and colluding with a society that appears to systematically neglect children's spirituality, the professional could offer a space that is spiritually conducive and accepting.

The findings highlight several important areas for future research and further theory development. Beyond gaining a greater understanding of the current research topic by using theoretical sampling from a larger pool of participants, it would be illuminating to investigate the experiences of children from different cultures where different social attitudes to spirituality prevail. Additionally it would be fascinating to learn more about the experiences of 'trusted adults' as well as children and in this way 
gain further insights into the apparent disparity that was reported between them in the present study. 


\section{References}

Altman, N., Briggs, R., Franel, J., Gensler, D., \& Pantone, P. (2002). Relational child psychotherapy. New York: Other Press.

Boyatzis, C.J. (2005). Religious and spiritual development in childhood. In R.F. Paloutzian \& C.L. Park (Eds.), Handbook of the psychology of religion and spirituality (pp. 123-142). New York: Guilford Press.

Boyatzis , C.J., \& Janicki, D. (2003). Parent-child communication about religion: A survey and diary assessment of unilateral transmission and bi-directional reciprocity. Review of Religious Research, 44, 252-270.

Charmaz, K. (2006). Constructing grounded theory: A practical guide through qualitative analysis. London: Sage.

Coles, R. (1990). The spiritual lives of children. Boston, MA: Houghton Mifflin.

Elliott, R., Fischer, C.T., \& Rennie, D.L. (1999). Evolving guidelines for publication of qualitative research studies in psychology and related fields. British Journal of Clinical Psychology. 38, 215-229.

Fiese, B.H., \& Bickham, N.L. (1998). Qualitative inquiry: An overview for pediatric psychology. Journal of Pediatric Psychology, 23, 79-86.

Fowler, J.W. (1981). Stages of faith: The psychology of human development and the quest for meaning. San Francisco, CA: Harper and Row.

Glaser, B.G. (1978). Theoretical sensitivity. Mill Valley, CA: The Sociology Press.

Glaser, B.G., \& Strauss, A.L. (1967). The discovery of grounded theory. Chicago, IL: Aldine.

Goldman, R. (1965) Readiness for religion. London: Routledge \& Kegan Paul.

Gross, J., \& Hayne, H. (1998). Drawing facilitates children’s verbal reports of emotionally laden events. Journal of Experimental Psychology. 4, 163-179. 
Grover, S. (2004). Why won't they listen to us? On giving power and voice to children participating in social research. Childhood. 11, 81-93.

Hardy, A. (1979). The spiritual nature of man. Oxford: Clarendon Press.

Hart, T. (2004). The secret spiritual world of children. London: Inner Ocean Publishing.

Hay, D. (2006). Something there: The biology of the human spirit. London: Darton Longman \& Todd.

Hay, D., \& Nye, R. (1998). The spirit of the child. London: Jessica Kingsley.

Helminiak, D.A. (1987). Spiritual development: An interdisciplinary study. Chicago, IL: Loyola University Press.

Hufton E. (2006). Parting gifts: The spiritual needs of children. Journal of Child Health Care. 10, 240-50.

Kirkpatrick, L.A. (1995). Attachment theory and religious experience. In R.W. Hood (Ed.), Handbook of religious experience (pp. 446-474). Birmingham, AL:

Religious Education Press.

Kwilecki, S (1999). Becoming religious. Cranbury, NJ: Associated University Press.

McSherry, W., \& Smith, J. (2007). How do children express their spiritual needs? Paediatric Nursing. 19(3), 17-20.

Myers, S.M. (1996). An interactive model of religiosity inheritance: The importance of family context. American Sociological Review. 61, 858-866.

Oser, F.K., Scarlett, W.G., \& Bucher, A. (2006). Religious and spiritual development throughout the lifespan. In W. Damon \& R.M. Lerner (Eds.), Handbook of child psychology (6 ${ }^{\text {th }}$ edn.) (pp. 942-998). Hoboken, NJ: Wiley.

Payne, S. (2007). Grounded theory. In E. Lyons \& A. Coyle (Eds.), Analysing qualitative data in psychology (pp. 65-86). London: Sage. 
Prentice, N.M., \& Gordin, D.A. (1986). Santa Claus and the Tooth Fairy for the Jewish child and parent. Journal of Genetic Psychology. 148, 139-151.

Rizzuto, A.M. (1979). The birth of the living god: A psychoanalytic study. Chicago, IL: University of Chicago Press.

Robinson, E. (1983). The original vision. New York: Seabury Press.

Roehlkepartain, E.C., Benson, P.L., King, P.E., \& Wagener, L.M. (2006). Spiritual development in childhood and adolescence: Moving to the scientific mainstream. In E.C. Roehlkepartain, P.E.King, L.M. Wagener \& P.L. Benson (Eds.), The handbook of spiritual development in childhood and adolescence (pp. 1-15). London: Sage.

Scott, D. (2003). Spirituality in child and youth care: Considering spiritual development and 'relational consciousness'. Child \& Youth Care Forum, 32, 117-31.

Smith, J.A. (1995). Semi-structured interviewing and qualitative analysis. In J.A. Smith, R. Harré, \& L. Langenhove (Eds.), Rethinking methods in psychology (pp. 1-26). London: Sage.

Smith, J.A., \& Eatough, V. (2007). Interpretative phenomenological analysis. In E. Lyons \& A. Coyle (Eds.), Analysing qualitative data in psychology (pp. 35-50). London: Sage.

Strauss, A.L., \& Corbin, J. (1990). Basics of qualitative research: Grounded theory procedures and techniques. Newbury Park, CA: Sage.

Taylor, J. (1989). Innocent wisdom: Children as spiritual guides. New York: Pilgrim Press.

United Nations (1990). United Nations convention on the rights of the child. Ottawa: Ministry of Supply and Services Canada. 
Walker, K., Caine-Bish, N., \& Wait, S. (2009). I like to jump on my trampoline: An analysis of drawings from 8-to12-year old children beginning a weight management program. Qualitative Health Research. 19, 907-917.

Yardley, L. (2000). Dilemmas in qualitative health research. Psychology and Health. $15,215-28$. 


\section{Tables}

Table 1: Religious affiliation of the research sample

\begin{tabular}{|ll|}
\hline Church of England & Ben \\
\hline Muslim & Sandra \\
\hline No affiliation & $\begin{array}{l}\text { Annie, Therese, Tina, Tom, Simon, } \\
\text { and Mike }\end{array}$ \\
\hline Not known & Laura \\
\hline
\end{tabular}

Table 2: The types of spiritual expressions discerned in the participants' accounts

\begin{tabular}{|c|c|}
\hline $\begin{array}{l}\text { Participants' } \\
\text { pseudonyms }\end{array}$ & 'Types' of spiritual expression \\
\hline $\begin{array}{l}\text { Sandra } \\
\text { Annie }\end{array}$ & $\begin{array}{l}\text { Direct personal experiences of spirituality (e.g. hearing angels } \\
\text { sing, hearing voices during prayer, out-of-body experiences, } \\
\text { continued bonds with a deceased, personal prayers and } \\
\text { conversations with God) }\end{array}$ \\
\hline $\begin{array}{l}\text { Therese } \\
\text { Ben } \\
\text { Tom }\end{array}$ & $\begin{array}{l}\text { Religious beliefs and questions (e.g. recounting Biblical stories, } \\
\text { questions about the validity of religious claims, negotiating } \\
\text { scientific and religious accounts of nature, moral reasoning and } \\
\text { development) }\end{array}$ \\
\hline $\begin{array}{l}\text { Simon } \\
\text { Tina } \\
\text { Mike }\end{array}$ & $\begin{array}{l}\text { Philosophical and existential questions (e.g. questions about } \\
\text { death, how nature 'works', 'what's behind the stars') }\end{array}$ \\
\hline Laura & $\begin{array}{l}\text { Not accessed by researcher or offered by participant (and } \\
\text { therefore does not feature in the analysis) }\end{array}$ \\
\hline
\end{tabular}


Table 3: Overview of categories and sub-categories

\begin{tabular}{|c|c|}
\hline Main categories & Sub-categories \\
\hline $\begin{array}{l}\text { Trusted adults } \\
\text { unavailable for child }\end{array}$ & $\begin{array}{l}\text { a. Too busy } \\
\text { b. Not a priority } \\
\text { c. Lack of space and privacy } \\
\text { d. Emotionally unavailable }\end{array}$ \\
\hline Adults' implicit guidance & \\
\hline $\begin{array}{l}\text { Child withholding from } \\
\text { trusted adult }\end{array}$ & $\begin{array}{l}\text { a. Reciprocity a condition } \\
\text { b. Withholding during the interview }\end{array}$ \\
\hline $\begin{array}{l}\text { Child accepting adults’' } \\
\text { implicit guidance }\end{array}$ & $\begin{array}{l}\text { a. Identifying with trusted adult } \\
\text { b. Adopting the spiritual stance of trusted adult } \\
\text { c. Projecting trusted adult onto the spiritual } \\
\text { world }\end{array}$ \\
\hline $\begin{array}{l}\text { Child isolating } \\
\text { themselves and making } \\
\text { sense of spirituality alone }\end{array}$ & $\begin{array}{l}\text { a. Spiritual isolation } \\
\text { b. Using imagination and play to make sense of } \\
\text { spirituality } \\
\text { c. Drawing on fictional and religious language } \\
\text { to make sense of spirituality } \\
\text { d. Using rational reasoning and logical } \\
\text { deduction to make sense of spirituality } \\
\text { e. Using the interviewer as a trusted adult }\end{array}$ \\
\hline $\begin{array}{l}\text { Space } \\
\text { wanted/appreciated }\end{array}$ & $\begin{array}{l}\text { a. The spiritual space wanted by the child } \\
\text { b. The spiritual space appreciated by the child }\end{array}$ \\
\hline
\end{tabular}




\section{Figure caption}

Figure 1: A model of the role trusted adults play in the spiritual lives of children.

Figure

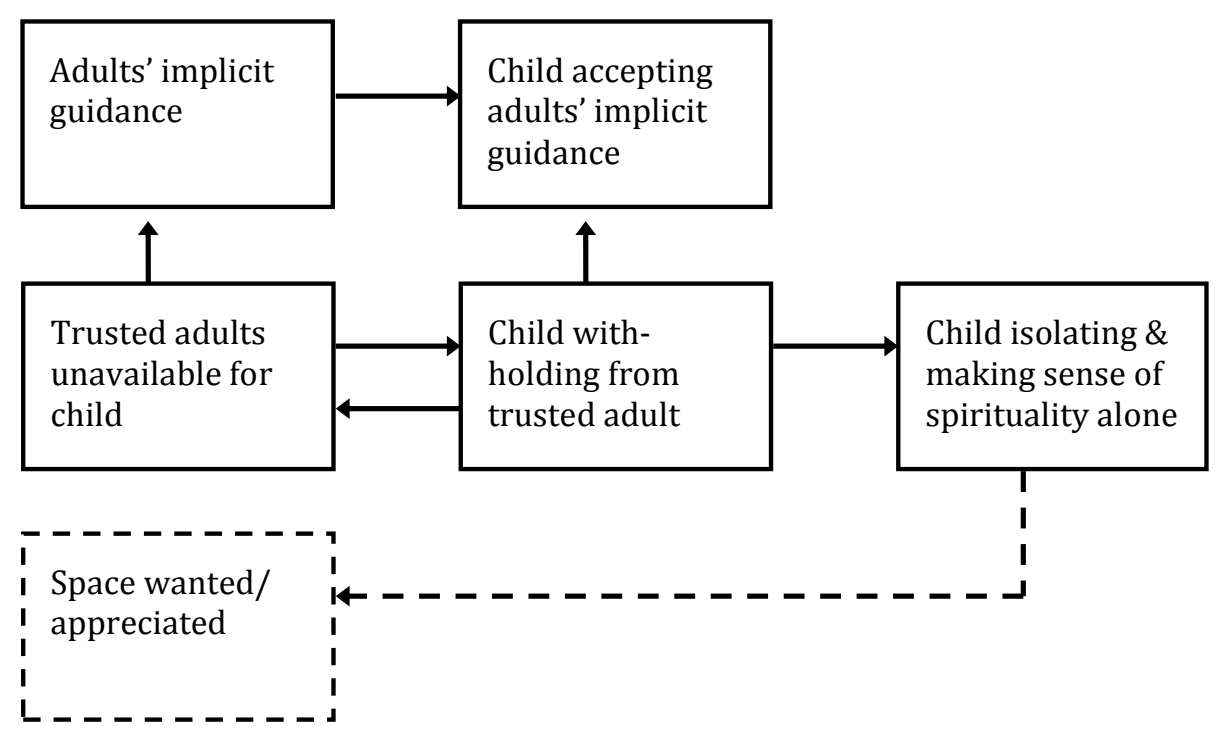

